\title{
Experiencing Loneliness by Seniors during the Covid-19 Pandemic on the Example of Poland and Slovakia
}

\author{
P. Jusko (Peter Jusko)' ${ }^{1}$ K. Kaczmarek (Klaudia Kaczmarek)², \\ R. Sivok (Roland Sivok) ${ }^{1}$
}

${ }^{1}$ Matej Bel University in Banska Bystrica, Faculty of Education, Original Article Banska Bystrica, SK.

${ }^{2}$ University of Applied Sciences in Piła, Piła, PL.

\section{E-mail address:}

Peter.jusko@umb.sk

\section{Reprint address:}

Peter Jusko

Matej Bel University in Banska Bystrica

Faculty of Education

Banska Bystrica

Slovakia

Source: Clinical Social Work and Health Intervention

Volume: 12

Issue: 3

Pages: $76-82$

Cited references: 16

\section{Reviewers:}

Zofia Szarota

Pedagogical University of Cracow, PL

Claus Muss

I-GAP Zurich, $\mathrm{CH}$

\section{Keywords:}

Loneliness. Pandemic. Isolation. Qualitative Research. Seniors. The Elderly. Social Welfare. Social Welfare Home. Poland. Slovakia.

\section{Publisher:}

International Society of Applied Preventive Medicine i-gap

CSWHI 2021; 12(3): 76 - 82; DOI: 10.22359/cswhi_12_3_13 CC Clinical Social Work and Health Intervention

"Loneliness is like a garden where the soul withers and the flowers stop smelling."

Marc Levy

Abstract:

Loneliness - a subjective, emotional state of feeling social isolation and being cut off from others. It comes and goes when life situation changes. In the case of chronic loneliness, it is experienced no matter what the circumstances. Loneliness functions in the temporal (time) dimension: it can be 
continuous, but it can also occur temporarily. The feeling of loneliness occurs in situations where the emotional bond is broken or in the case of isolation. The aim of this article is to address the problem of seniors' loneliness which is caused by the limitations of the Covid-19 pandemic. The participants of the study are seniors living in Poland and Slovakia. Research conducted in Poland, with two elderly women over 70 , living in a small fishing village in the north of the country, shows that they experience unpleasant states of loneliness despite having adequate relationships with other people. As observations show, the increase in loneliness is caused by conditions that require the observance of precautionary measures related to the pandemic and restrictions on socializing and conducting classes in senior clubs. The above factors result in shallowing interpersonal interactions; weakening interpersonal relations; contribute to more superficial contacts mainly by telephone. Seniors who are in care at the Retirement Home and Nursing Home in Slovakia also admit to feeling lonely, though not directly. From the conversation, however, it can be concluded that this condition does not result directly from pandemic limitations, but rather from too little contact with loved ones. The presence of other residents and staff, contact with people, meals, activities and conversations significantly fill the time during the day. The study was aimed at checking the facts of loneliness faced by seniors living in Slovakia and Poland as well as providing information about their views on their situation. The aim of the study is also to indicate the direction that will be helpful in combating and preventing such a pejorative phenomenon as loneliness. The research was conducted in the form of an interview. In order for the quality of the interviews to be as high as possible, the respondents were selected from various backgrounds. In Poland, there were two single women, aged over 70, living in a tiny fishing village; in Slovakia they were clients of the Retirement Home and the Nursing Home in Rimavska Sobota. The authors of the texts on the situation in Poland and Slovakia would like to add that the respondents waited with interest for contact from the authors of the publication; were happy that they could speak; that there were people who were interested in their problems. The researchers tried to comprehensively present the analysis of the obtained data, situations and statements of the respondents and, using the bricollage technique, to interpret it in detail. The most important issues raised in the interviews were additionally summarized in the conclusions.

${ }^{1}$ Francine Russo. Toxic loneliness. "Science World". 319 (3/2018), pp. 58-63, 2018-03. Prószyński Media.

${ }^{2}$ People over 60 years of age, 3 people from Slovakia and 2 from Poland participated in the study. 


\section{The phenomenon of loneliness}

In the literature it is not easy to find an unambiguous definition of this phenomenon and a detailed and in-depth method of measuring loneliness. Often the concept of loneliness is equated with a sense of loneliness, such an interpretation is represented, among others, by Józef Rembowski ${ }^{3}$, Janusz Gajda ${ }^{4} \&$ Maria Łopatkowa ${ }^{5}$. We can also meet authors who distinguish between the terms "loneliness" and „loneliness“ - such as John G. McGraw ${ }^{6}$, Krystyna Kmiecik-Baran ${ }^{7}$, Maria Szyszkowska ${ }^{8}$ or Jan Szczepański ${ }^{9}$. This article uses the definition of Jan Szczepański for whom ,,isolation, lack of understanding, lack of mutual understanding, lack of interest in a person and their affairs are the most important factors in the phenomenon of social and mental loneliness". According to Szczepański, loneliness and loneliness are two different states. Not every person who is alone feels lonely. This is exactly what happens in the case of our respondents, one of them was not as troublesome as the other because of the isolation as a result of the pandemic.

\section{Issue 1 deals with feelings related to limitations.}

Both ladies were asked if the restrictions resulting from the pandemic had any impact on their well-being. The first of them replied:

„I have always believed that an intelligent person is never bored and I organize my time in accordance with this principle. I like reading books, walking on the beach, exercising every day, solving crosswords, and being in my garden. I am a widow, since my husband died of pancreatic cancer; my life has changed but I have to live on! I have developed daily rituals that determine my daily schedule. In addition, I have contact with a few friends from college with whom I regularly talk on the phone; sometimes they come and visit me for a week or two. Then we go to Kołobrzeg, to the beautician, for a good dinner".

Unfortunately, the second respondent felt the isolation in a completely different way:

„I feel very lonely since they closed the senior club and took away all our classes; this loneliness and emptiness became unbearable! At least 3 times a week I used to go to English, yoga, healthy spine classes, manual classes,. I was meeting my friends. We always laughed; talked; listened; told each other things. We advised each other; we supported each other in various ailments; we exchanged experiences. Each person knew they had a purpose. You had to get up, get dressed, put on makeup... and when they took it away, I even lost my appetite. Still alone, I don't even want to cook for myself, you see how I look ... $46 \mathrm{~kg}$, I got my legs like matches from this grief (...) I was so depressed when my daughter saw me, persuaded me to visit a psychologist.

\section{Feelings of loneliness during a pandemic}

\section{Issue 2; Feelings accompanying loneliness in the age of the Covid-19 virus.}

Both ladies were asked about their feelings in the moments of isolation. They were asked to indicate a few of the following: fear, regret, reluctance, pain, sadness, anger, sense of injustice, understanding of the situation, sense of responsibility for oneself and others, the need to adapt to the prevailing conditions. The first of the ladies consistently and with understanding for the circumstances occurring mentioned:

„I had no pain or fear. Anxiety maybe only for a moment how it all started and it was not known what would happen next, such uncer-

\footnotetext{
${ }^{3}$ See J. Rembowski, Loneliness, Gdańsk 1992

${ }^{4}$ J. Gajda, Loneliness and Culture, Warsaw 1987,

${ }^{5}$ M. Łopatkowa, Loneliness of a Child, Warsaw 1983,

${ }^{6}$ J. G. McGraw, Loneliness: hunger for closeness / meaning, "Zdrowie Psychiczne" 1995 No. 1-2, pp. 58-65

${ }^{7} \mathrm{~K}$. Kmiecik-Baran, The sense of loneliness - a characteristic of the phenomenon, "Przegląd Psychologiczny" 1988 No. 4, pp. 1081-1095,

${ }^{8}$ M. Szyszkowska, Lost in Everyday Life, Warsaw 2000,

9 J. Szczepański, Human Affairs, Warsaw 1984,
} 
tainty more so. You had to stay at home, so I stayed. I thought that we were obliged to be responsible in such a difficult situation“(...). Today, I think that maybe some actions were exaggerated, but I do not feel strongly negative emotions about it anyway. Nobody knew what was going to happen. (...) I felt a bit sorry that I couldn't go to the gym or coffee shop or have my favorite squeezed juice, but they weren't some strongly negative emotions".

In the second respondent we are dealing with a completely different color of feelings and emotions:

„I felt anger and regret above all, I was furious that it is impossible to go anywhere or meet anyone. I am aware that this disease can be cruel in its consequences, but I do not think that it is for everyone and I do not share such strict restrictions; this closure is terrible! ,(...) I went through covida. I was broken for a week. Such a flu there is no point in dramatizing it. I am not afraid of it. (...) As for the accompanying feelings, I would like to add that I feel sick when I hear about this 4th wave."

Summing up the research conducted in Poland, each of the respondents has a completely different view and feelings associated with isolation during the Covid-19 pandemic. Both ladies live alone in the same village, by the sea, in Poland. They both have children; are active drivers; have friends and interests; both have a good financial situation; good health. As the study shows, they experienced the time of isolation very differently: each of them was accompanied by different emotions and observations towards the surrounding situations. Each of them assures that they were missing something in this difficult period, but the feeling of this lack takes on a different intensity in each of them. It was undoubtedly not an easy time for either of them. However, as the study shows, the ability to cope with loneliness does not only apply to personal situations, both ladies have it quite similar to each other. Character factors predominate here, such as: sensitivity to changes; the ability to adapt to a new situation; susceptibility to stress; the need for direct contact with other people; the ability to spend time with oneself; the need to change locations and leave the house.
In Slovakia, we conducted interviews in the Retirement Home and the Social Services Home in Rimavská Sobota, where we addressed 3 clients over the age of 60 for an interview. One interview was with two participants and the other with only one participant. In the following text, we will interpret our findings in the context of our research focus. We used open coding and the description method. For a better idea of the described findings, we took the liberty of quoting some statements of the participants in the text.

\section{Importance of isolation during an exacerbated pandemic situation}

Participants told us from the beginning that they did not notice any changes during the period of the increased number of positive cases of Covid-19 and that they were not very burdened by the overall problem situation. Nothing has changed in the retirement home and „Everything was fine".

During the negative test they could leave the facility on the basis of a signed exit form if they needed to go e.g. for a walk. The operation of the facility like all facilities and institutions at the time had stricter measures to prevent the spread of Covid-19. If the family and loved ones came, the client who wanted to visit him was not allowed to do so, and if they brought something to the client, they could only leave it behind the entrance gate.

„When someone brought something, it was only passed through the gate."

„If we have any problems, the caretakers will talk to us and remember what they can."

„One next to a very golden lady, we debated with her like this.“

The importance of isolation for them was therefore seen in particular in the restrictions related to the ban on visits and measures such as wearing robes, hand disinfection, distances, etc. In order to describe the importance of isolation during a worsened pandemic situation for the clients of the mentioned facility, we will briefly describe how they perceive their stay. According to the statements of our participants, the overall perception of the stay in the classification is divided into two groups: One enjoys almost every activity in the facility in almost every circumstance:

„I am happy with everything“;

he other group performs the tasks and activi- 
ties they have because they have nothing else left but would rather live in a home environment: „We will do what they tell us and we still don't have anything on the robot, at least something. So what they give us, we will do it, but it would be better at home."

Isolation was spent differently by clients depending on whether they were positive for Covid-19 or not. Those who were positive were transferred to quarantine rooms, respectively. These were their rooms in which they were separated and could not leave. Food was brought to them regularly, which was basically the only contact they had at the time. Complications associated with being in a quarantine room were therefore solitude and the fact that they often had no one to talk to if no one in the room was quarantined with them at the time. Furthermore, these were also common things, such as providing ventilation, opening windows that some clients are not used to as this is usually provided by caregivers.

„I just had to open the window myself to make me feel better."

But when they overcame them; they did activities they don't usually do; they were happier; said they felt a little better. In the event that such clients have expired their quarantine, or in the case of clients who have been negative for Covid-19, they have not, in principle, experienced any changes and have spent most of their time indoors. „Cards sometimes, people play, or something they give.“

\section{Feelings of lonely seniors}

Although some participants did not directly admit loneliness, they admitted that they lacked family and conversations with them. However, some clients do not feel alone, just because of the isolation caused by the pandemic situation, they basically perceive the isolation in the facility can be said permanently. However, as we have mentioned, some of the facilities are also said to be satisfied with everything, but the most pressing problem they feel is that their close family does not visit them, even if the situation allows, so they perceived the worsened pandemic situation almost as much as normal days:

„I haven't seen my family in a year, they live here and they won't even come to visit me."

It should be mentioned that some clients who went through the disease experienced this period without significant health complications and some experienced pain, coughing, non-control and other complications. As they say, it is ,,a very, very bad disease." During this period, they had to be in the quarantine rooms mentioned, where the only contact was often when the caretakers brought food to their room; where they still talked only for a while in compliance with established measures. They spent their time in quarantine, just breathing, and when they felt pain or a significant mental discomfort, they called a nurse who gave them medication and talked to them. An ordinary conversation was incredibly much for them, and they appreciated such an interview very much, because as they themselves state,

„We immediately felt a little better.“

Thus, any interpersonal contact: a short conversation with the staff; a phone call with loved ones; an interview with another client in a facility with whom they got along well helped significantly in the feeling of loneliness, but also in health complications.

„My friend, I'll tell you all this; we'll tell each other everything; they'll advise me;

we'll talk about it; then it's a little easier for the soul that I'm sued, cried."

Often, however, clients can talk in such a confidential way only with friends from the facility or staff because some clients are not contacted by the family even by phone:

„I'm waiting for the phone and I'm thinking of my son, but he's not the one calling me."

They also perceived as a very positive effect on mental well-being the tone in which the nurse spoke to them, even in the case of pain or other suffering. The kind tone of the local nurse was supposed to have literally beneficial effects on the physical and health condition of the clients of this facility:

„The babysitter is very golden; she has such a very nice voice;

you really just have to hear and you are immediately relieved".

Telling the problems of a loved one and expressing the compassion of the person we call our troubles thus provides a way to overcome loneliness. Compassion is an understanding of the sufferings and problems one feels; it is basically compassion. In connection with the feeling of 
loneliness, a pleasant society naturally helps the most. But compassion represents the creation of a warm atmosphere for a person who experiences loneliness and problems (Čáp, Palenčár 2012)

\section{Approaches to healthcare}

Access of seniors to healthcare in the facility has not changed significantly. The nurses and social workers handled all the necessary matters related to the equipment of the examination: „They'll take care of everything.“

The waiting time for examinations was approximately one week which is the normal waiting time even if the worsened pandemic situation was not present. However, many patients allegedly did not undergo visits to the doctor during the worsening pandemic situation, and only those clients who experienced significant pain and difficulties went for the examination:

„He who was sick went.“

The functioning of the outpatient clinic in Slovakia during the pandemic was still ensured, but it was recommended that patients, if possible, replace the personal consultation with the doctor by telephone and prescribe medication by doctors exclusively electronically. Examination by a specialist doctor at the time of the increased number of Covid-19 cases also did not require the issuance of an exchange ticket by a district doctor (https://www.health.gov.sk/Clanok?covid-19-1510-2020-lekari-postup)

\section{Retrospective view of the period of worsened pandemic situation in the facility}

During the pandemic, clients had the opportunity to talk and discuss with clients from the facility and staff. If they were not positive: they liked to take part in social activities; they talked about their family, children, grandchildren; about recipes which they later had the opportunity to try. During the pandemic they: tried new recipes, exchanged information that was interesting to them; watched a program on TV together:

„We debated together, we boiled, we baked, we laughed, and then we missed the TV.“

The Covid-19 pandemic has hit everyone and caused many inconveniences to people around the world. Nevertheless, there are also the ,positive aspects of the pandemic", which gave people the opportunity to address things they did not normally do and thus experienced moments that had the potential to unite them a little more. It is at a time when everything is not quite right that people often find the true value of what they have and what is essential in life. Our participants are older people, but they are all the more aware of what is important in life even in the case of problems that affect us. The important thing is a cohesive family; strong interpersonal relationships; a kind understanding approach to a person in difficulty.

\section{References}

1. BERG-WEGER M, MORLEY J E (2020) Loneliness and Social Isolation in Older Adults during the COVID-19 Pandemic: Implications for Gerontological Social Work. In: J Nutr Health Aging, Vol.24, 2020, pp.456-458. DOI: https://doi.org/10.1007/s 12603-020-1366-8

2. COVID-19: Operation of ambulances during pandemic. https://www.health.gov.sk/Clanok?covid-19-15-10-2020-lekari-postup, 15.10.2020, 15:16.

3. CAP J, PALENCAR M (2012) Death and the consciousness of mortality. Bratislava: IRIS 2012, 199p. ISBN 978-80-89256-96-9.

4. DAHLBERG L (2021) Loneliness during the COVID-19 pandemic. In:, Aging \& Mental Health, Vol.25, No.7, 2021, pp.11611164, DOI: 10.1080/13607863.2021.187519 5

5. RUSSO F (2018) Toxic loneliness. In: Swiat Nauki . Vol.319, No.3, 2018, pp. 58-63. ISSN 1689-0191.

6. GAJDA J (1987) Loneliness and culture, Warszawa: Instytut Wydawniczy Związków Zawodowych, 1987, p. 230. ISBN 9788320205459.

7. HANGONI T, CEHELSKA D, SIP M (2015) Social counseling for seniors. Presov: PU, 2015, p. 209. ISBN 978-80-555-1058-3.

8. KMIECIK-BARAN K (1988) The sense of loneliness - a characteristic of the phenomenon. In: Przegląd Psychologiczny, Vol.3, No.4, 1988, pp. 1081-1095. ISSN 00485675.

9. ŁOPATKOWA M (1983) The loneliness of the child, Warszawa: Czytelnik, 1983, p. 147. ISBN 9788320205459.

10. LUKACOVA V (2018) Experiencing social 
loneliness and perceived social support of seniors in the institutional environment. Presov: PU, 2018. https://www.pulib.sk/ web/kniznica/elpub/dokument/Kvasnakova3/ subor/Lukacova_Veronika.pdf. 2.5.2018, 12:21.

11. MCGRAW J G (1995) Loneliness, its nature and forms: An existential perspective. In: Man and World, Vol.28, No.1, pp.43-64. DOI: $10.1007 / \mathrm{BF} 01278458$.

12. REMBOWSKI J (1992) Independence, Gdańsk: Wyd.UG, 1992, p. 157. ISBN 8370174450.

13. SZCZEPANSKI J (1984) Human affairs. Warszawa: Allegro, 1984, p. 349. ISBN 9788307001319.

14. SZYSZKOWSKA M (2000) Lost in Everyday Life. Warsaw: Your Style, Scientific publishing house, 2000, p. 112. ISBN 83900112-4-7.

15. WHITEHEAD B R, TOROSSIAN E (2021) Older Adults' Experience of the COVID-19 Pandemic: A Mixed-Methods Analysis of Stresses and Joys. In: The Gerontologist, Vol.61, No.1, 2021, pp.36-47. DOI:https:// doi.org/10.1093/geront/gnaa126.

16. WU B (2020) Social isolation and loneliness among older adults in the context of COVID19: a global challenge. In: Glob Health Res Policy, Vol.5, No.27, 2020. DOI: https://doi.org/10.1186/s41256-020-00154-3. 